Public health

\section{Canine leptospirosis in Canada: a veterinarian's perspective}

$\infty$

See related article page 399

$\mathrm{L}$ eptospirosis is a zoonotic bacterial disease that appears to be becoming more prevalent in Canada. The number of cases of leptospirosis in dogs in Canada and the United States has increased markedly in the last decade. ${ }^{1-10}$ Transmission to humans is rare, although a few human cases in which leptospirosis was acquired from dogs have been recently recognized in Ontario and Quebec. ${ }^{7,10}$

Between 1998 and 2005, the number of canine sera samples submitted to the Animal Health Laboratory at the University of Guelph for leptospirosis serologic testing increased from 42 to $\mathrm{I}_{3} 6$. In 2005 , 25 I samples (22\%) were positive for leptospirosis and 404 (36\%) were "suspicious." ${ }^{6}$ There has been no change in laboratory diagnostic procedures over this time, so the increases in cases may reflect increased awareness and, more concerningly, a true increase in the incidence and level of disease activity in Ontario. There has been a similar trend Quebec, where the number of positive canine serodiagnoses rose from 5 in 1998 to 56 in $2006 .^{7}$ The number of canine cases has also increased in New Brunswick (Dr James Goltz, New Brunswick Ministry of Agriculture and Aquaculture, personal communication, 2005). Although few cases have been documented in British Columbia, diagnoses of canine leptospirosis have increased recently in nearby Washington State, particularly in the greater Seattle area. ${ }^{8}$ Currently the Prairie provinces report few case of canine leptospirosis. In Canada, dogs are usually tested for the following leptospirosis serotypes: autumnalis, bratislava, canicola, icterohemorrhagiae, grippotyphosa and pomona. However, these tests may not identify the infecting serotype because in acute canine leptospirosis, there is often a confusing pattern of cross-reactivity against multiple serotypes. ${ }^{1,5,6}$

Canine leptospirosis can affect dogs in both urban and suburban environments. Wild and domestic animals, in- cluding raccoons, skunks, dogs and rats, can act as reservoirs. The increased number of cases observed in certain parts of Canada likely relates to a combination of increased infection among the large number of raccoons that inhabit urban and suburban settings, ecological conditions brought about by a warming climate that favours the survival of this fastidious organism and increased awareness of the infection by veterinarians. ${ }^{1}$ Leptospirosis in Canadian dogs occurs largely in the fall (September-December) when the weather is both warm and wet. The infecting serotypes observed more recently in North American dogs are largely grippotyphosa and pomona, which are acquired from urban raccoons and skunks. In contrast, the serotypes canicola and icterohemorrhagiae are acquired from dogs and rats respectively. These emerging trends suggest that the epidemiology of infection, including the infecting serotypes and the role of raccoons, needs to be clarified.

Leptospirosis in dogs can be a very serious disease, and the disease may present as peracute, acute, subacute or chronic (Box I). ${ }^{3,4}$ Subacute disease is the most commonly recognized form of the disease, but many leptospiral infections in dogs are chronic and the majority are probably subclinical. Unlike humans, aseptic meningitis is not recognized. An additional diagnostic challenge to veterinarians, is the failure intravascular coagulation). coagulopathy and vascular injury; death. because of vasculitis causing muscle damage.

\section{Key points of the article}

- There has been a marked increase in canine leptospirosis in North America in the last decade.

- Suburban raccoons may be a reservoir.

- Climate change may enhance bacterial survival.

- An effective canine vaccine is available to control wildlife-acquired serotypes.

- Reporting of canine leptospirosis should be mandatory.

(because of cost) to obtain a "convalescent" serum sample.

Dogs are thought to shed wildlifeacquired leptospires in their urine for up to 6 weeks after infection, although they will shed the dog-adapted serotype canicola for life. Thus, people are at risk for infection not only from dogs who are obviously sick but also from subclinically infected animals who appear healthy. Fortunately, the canicola serotype has been largely eradicated by canine vaccination.

A "4-way" vaccine for dogs that includes the serotypes grippotyphosa and pomona was introduced in Canada in 200I. Annual vaccination controls these infections effectively and is increasingly recommended by many veterinarians. The extent of vaccination coverage and its population effect (herd immunity) has not been documented.

The increased level of disease activity among dogs prompts questions about increased risk of transmission to humans. Recently, there have been reports of small numbers of cases of infections acquired from dogs by veterinary staff ${ }^{10}$ and by the owners of infected dogs. ${ }^{7,9,10}$ Unfortunately, docu-

Box 1: Clinical presentations of canine leptospirosis ${ }^{3,4}$

- Peracute disease (rare): death, following short-lasting signs of shock (disseminated

- Acute disease (uncommon): pyrexia; muscle tenderness; endotoxic shock with

- Subacute disease (most common form recognized clinically): pyrexia, mucosal petechiation; anorexia; signs of renal failure including vomiting, polyuria, polydipsia, sometimes anuria; jaundice; sometimes diarrhea; reluctance to move

- Chronic (uncommon): jaundice with chronic active hepatitis; anterior uveitis.

- Clinically inapparent (probably the majority of cases). 
mentation has been poor. The overall prevalence appears still to be very low, although no population surveys have been done. A recent case of a family's exposure to an infected pet, which was brought to the attention of a local public health unit, prompted the accompanying Public Health column on leptospirosis. ${ }^{11}$

Perhaps because of the lack of awareness of leptospirosis among Canadian physicians and the relative rarity of human cases in Canada, a few of the recognized cases involved selfdiagnosis or diagnosis by veterinarians ${ }^{9}$ and subsequent confirmation by health care professionals. Canadian physicians need to be aware of the risk that canine leptospirosis acquired from urban wildlife, notably raccoons, poses to humans. It would be a useful if veterinarians were required to report canine cases of leptospirosis to public health authorities. This may improve understanding about the level of risk and possibly assist in the detection and prevention of secondary human cases. Mandatory re- porting would likely increase veterinary attempts to control the canine (and therefore human) infection by vaccination, and it would increase medical awareness of this problem.

John Prescott VetMB PhD

Department of Pathobiology

Centre for Public Health and Zoonosis

Ontario Veterinary College

University of Guelph

Guelph, Ont.

This article has been peer reviewed.

Competing interests: None declared.

\section{REFERENCES}

I. Prescott JF, McEwen B, Taylor J, et al. Resurgence of leptospirosis in dogs in Ontario: recent findings. Can Vet J 2002;43:955-6r.

2. Ward MP, Glickman LT, Guptill LE. Prevalence of and risk factors for leptospirosis among dogs in the United States and Canada: 677 cases (I970I998). J Am Vet Med Assoc 2002;220:53-8.

3. Greene CE, Sykes JE, Brown CA, et al. Leptospirosis. In: Greene CE, editors. Infectious diseases of the dog and cat. 3 rd ed. St. Louis (MO): WB Saunders; 2006. p. 402-I7.

4. Langston CE, Heuter KJ. Leptospirosis: a reemerging zoonotic disease. Emerging and Re- emerging Infectious Diseases. Vet Clin North Am Small Anim Pract 2003; 33: 791-807

5. Moore GE, Guptill LF, Glickman NW, et al. Canine leptospirosis, United States, 2002-2004. Emerg Infect Dis 2006;12:50I-3.

6. McEwen B, Ojkic D, Prescott JF. Canine leptospirosis update. Animal Health Laboratory Newsletter. Issue ro. Guelph (ON): The University of Guelph; 2006. p. 24. Available: www.labservices.uoguelph .ca/labserv/units/ahl/files/ANwslio-3.pdf (accessed 2007 Dec I2).

7. Vincent C, Munger C, Labrecque O, et al. La leptospirose: Cas de transmission d'un chien à un humain. Réseau d'Alerte et d'Information Zoosanitaire (RAIZO) Bulletin Zoosanitaire [no.5I] The Bulletin; 2007. Available: www.mapaq.gouv.qc .ca/NR/rdonlyres/FiDE44C9-4DBD-4oD8-96BF-E4 $\mathrm{CCBBF}_{33} 646 / 0 /$ BulletinLeptocanine2006_5I.pdf (accessed 2007 Dec I2).

8. Leslie $M$, Baer R. Increase in reported human and canine leptospirosis in Washington. Washington: Washington State Department of Health. Available: www.doh.wa.gov/EHSPHL/Epidemiology/CD /ci/caninelepto.htm (accessed 2007 Dec I2).

9. Wyeth Animal Health. Leptospirosis Information. www.leptoinfo.com/User/Docs/Leptoinfo.comLepto $\% 20 H e a l t h \% 20 \& \% 20$ Safety\%2oBulletin.pdf (accessed 2008 Jan 9).

Io. Allard R, Bédard L. Explanatory notes on statistics for reportable disease (Maladies infectieuses a déclaration obligitaire) and other infectious diseases under surveillance, period 3, year 2006 (weeks 9-I2 [26 February 2006 to 25 March 2006). Montréal, Que: Montréal Public Health Department; 2006. Available: www.santepub-mtl.qc.ca /Mi/surveillance/mado/archives/english/2006/notes 2006.pdf (accessed 2008 Jan 9).

II. Brown K, Prescott J. Leptospirosis in the family dog: a public health perspective. $C M A J$ 2008;178:399-40I. 